\title{
Positive impact of COVID-19 induced lockdown on the environment of India's national capital, Delhi
}

\author{
Niti Yashvardhini ${ }^{1} \cdot$ Amit Kumar $^{2} \cdot$ Manjush Gaurav $^{2} \cdot$ Kumar Sayrav $^{3} \cdot$ \\ Deepak Kumar Jha ${ }^{4}(\mathbb{D}$
}

Received: 23 June 2021 / Revised: 7 December 2021 / Accepted: 12 December 2021/Published online: 27 December 2021

(C) Korean Spatial Information Society 2021

\begin{abstract}
The rapid emergence of novel coronavirus disease has shown some positive impact on the health of natural environment. Present study was aimed to assess the impact of COVID-19 induced lockdown on the water quality of Yamuna River and air quality of national capital territory, Delhi. Significant decline in air quality pollutants like $\mathrm{NH}_{3}, \mathrm{SO}_{2}, \mathrm{CO}, \mathrm{PM}_{2.5}, \mathrm{NO}_{2}$ were observed. The major decline was found in the levels of $\mathrm{PM}_{2.5}, \mathrm{SO}_{2}, \mathrm{NO}_{2}$ and $\mathrm{NH}_{3}$. The less significant decline was seen in the $\mathrm{CO}$ level during the lockdown period. Furthermore, the overall decline in the concentrations of BOD, COD and increase in $\mathrm{pH}$ suggesting an improvement in Yamuna water during the lockdown. However, the concentration of DO was found insignificant during the lockdown period. Additionally, comparative analysis of morbidity, mortality as well causalities during this period has also been recorded to establish correlation of pre and post COVID-19 situations. Altogether, present study is found to be a useful supplement for policymakers because marked improvements in the water and air quality indices have been observed after enforcement of lockdown leading to control of the various pollution sources. Therefore, periodical lockdown can be
\end{abstract}

Niti Yashvardhini and Deepak Kumar Jha have contributed equally.

Deepak Kumar Jha

deepakkumarjha01@gmail.com

1 Department of Microbiology, Patna Women's College, Patna 800001, India

2 Department of Botany, Patna University, Patna 800005, India

3 Department of Chemistry, V.K.S. University, Ara 802301, India

4 Department of Zoology, P. C. Vigyan Mahavidyalaya, J. P. University, Chapra 841301, India utilized as an effective mitigation measures for natures' restoration.

Keyword COVID-19 • Lockdown · Water quality index · Air quality index · Delhi national capital territory · Yamuna river

\section{Introduction}

SARS-CoV-2 is an etiolating agent of current novel human coronavirus disease (COVID-19) reported from wet sea food market of Wuhan city (Hubei province), China, in December 2019 [1, 2]. COVID-19 is a highly contagious disease that induces mild to severe respiratory illness in infected individuals [3]. Due to its rapid spread, coronavirus outbreak has been declared as public health emergency of international concern by the World Health Organization (WHO) on 30th January 2020 [4]. As of June 1st, 2021, worldwide 170,812,850 confirmed cases of COVID-19 have been reported to WHO including 3,557,586 casualties (WHO COVID-19 Dashboard).

The devastations caused by COVID-19 pandemic has adversely affected almost all aspects of human life as well as economic development of twenty-first century globally. Due to its ability to cause rapid infection and mortality, many countries around the world have adopted several precautionary measures, such as massive testing, social distancing, sanitization of hands at regular intervals and quarantine etc. to contain the transmissibility of this highly contagious viral disease [5-7]. Similarly, the Government of India had declared a lockdown since the midnight of 24th March 2020, to break the chains of coronavirus spread. With work halting, industries become non-functional and vehicular transportation systems including 
railways and public transport almost remained standstill, leading to the improvement in the parameters of air quality across India's big cities [8,9]. Simultaneously, the water quality indices of many rivers across the country including Yamuna River were found improving [10-12].

In the present study, an attempt was made to analyze the positive impact of lockdown on the environmental parameters like air quality index of Delhi region and water quality of river Yamuna (Delhi). Previously, numerous studies have been carried out on the assessment of water quality and health of the river. Upadhyay et al. (2011) [13] have reported that Yamuna is one of the worst polluted rivers in India, mainly in, Delhi. Therefore, it is highly pertinent to evaluate the water quality of Yamuna River during the period of lockdown as well as air quality of densely populated city like Delhi for the assessment of natural recovery of the environments. The data of our study revealed that environmental parameters including water quality index (like pH, DO, BOD, COD) and air quality index $\left(\mathrm{NH}_{3}, \mathrm{SO}_{2}, \mathrm{CO}, \mathrm{PM}_{2.5}, \mathrm{NO}_{2}\right)$ have appeared to be giving positive sign towards restoring nature. This showed eco-restoration of nature leading to improvements in the environmental parameters during COVID-19 induced lockdown which will open new horizons for the environmental sustainability and will also help policymakers to amend policy for sustainable development. Furthermore, comparative analysis of morbidity, mortality and recovery during this period has also been recorded to establish correlation between pre and post COVID-19 situations.

\section{Methods}

\subsection{Study area}

The present work involves the study area as Delhi, the capital of India, situated on the western bank of the Yamuna River in the north-central part of the country. Delhi being the largest city in the country is one of the overcrowded cities amongst the world. The location of Delhi lies between $28.7041^{\circ}$ North latitude and $77.1025^{\circ}$ East latitude. The population of Delhi as per census 2011 was 1.42 lakhs inhabitants with a population growth rate of $1.39 \%$ per year. Delhi covers a land area of $1484 \mathrm{~km}^{2}$ with 4057 individual per $\mathrm{km}^{2}$.

\subsection{Data collection}

Total number of COVID-19 confirmed cases, number of cured cases and death occurred due coronavirus infections were recorded from the website (https://www.kaggle.com) [14]. The parameters of Air Quality Index (AQI) [15] like $\mathrm{PM}_{2.5}, \mathrm{NH}_{3}, \mathrm{SO}_{2}, \mathrm{NO}_{2}$, and $\mathrm{CO}$ were extracted from (https://app.cpcbccr.com) Central Pollution Control Board (CPCB) website. To detect the actual impact of lockdown on the AQI of Delhi, the National Air Quality Index (NAQI) website was used as the data source. The parameters of Water Quality Index (WQI) [16] like DO (Dissolved Oxygen), pH, BOD (Biological Oxygen Demand) and COD (Chemical Oxygen Demand) were collected from the Delhi Pollution Control Committee (DPCC) (https:// www.dpcc.delhigovt.nic.in) [17]. In the present study, three sites were selected for the analysis of WQI of river Yamuna viz. Palla, Nizamuddin Bridge and Agra canal (Jaitpur) stations from January 2020 to March 2021. This period was divided into pre-lockdown phase (JanuaryMarch, 2020), lockdown phase (April and May, 2020) and post-lockdown phase (June 2020-March 2021).

\subsection{Statistical analysis}

To investigate the impact of the lockdown on Delhi's air and water quality, three sets of data were collected from the above-mentioned sources at 10-days intervals for air quality and per-month data for water quality from January 2020 to March 2021. One way ANOVA test was performed with a hypothesis for all different AQI and WQI parameters that mean pollutant concentration has no effect of lockdown. For all the parameters the $p$ value $<0.05$, leading to rejection of null hypothesis implying that lockdown had significant impact on concentration of most of the parameters including $\mathrm{PM}_{2.5}, \mathrm{NH}_{3}, \mathrm{SO}_{2}, \mathrm{NO}_{2}$, and $\mathrm{CO}$ and also on $\mathrm{pH}, \mathrm{DO}, \mathrm{BOD}$ and COD values.

\section{Results}

\subsection{Effect of lockdown on air quality index}

For the study of the impact of lockdown on air quality of India's capital (Delhi), data was collected on 10 days intervals for five major pollutants $\mathrm{PM}_{2.5}, \mathrm{SO}_{2}, \mathrm{NO}_{2}, \mathrm{CO}$ and $\mathrm{NH}_{3}$ from CPCB website for further analysis. Our study involved the time period pre-lockdown as JanuaryMarch 2020, during lockdown as April and May 2020, whereas post-lockdown as June 2020-March 2021. The average concentration of different pollutants before the lockdown (From January to March 2020) was $\mathrm{PM}_{2.5}$ $\left(188.77 \pm 82.17 \mu \mathrm{g} / \mathrm{m}^{3}\right), \quad \mathrm{NO}_{2} \quad\left(52.77 \pm 14.68 \mu \mathrm{g} / \mathrm{m}^{3}\right)$, $\mathrm{NH}_{3}\left(6.66 \pm 2.17 \mu \mathrm{g} / \mathrm{m}^{3}\right) \mathrm{SO}_{2}\left(20.55 \pm 10.12 \mu \mathrm{g} / \mathrm{m}^{3}\right)$ and $\mathrm{CO}\left(36.88 \pm 10.12 \mathrm{mg} / \mathrm{m}^{3}\right)$ as shown in Table 1 [18]. The nationwide lockdown was imposed on 24th March 2020 due to the COVID-19 pandemic. Due to this lockdown, the major sources of air pollution like vehicles, power plants, industries were halted and hence its impact was seen on air quality of Delhi, which is a pollution hub of the country. 
Table 1 Showing air quality index parameters during pre, during and post lockdown period of COVID-19

\begin{tabular}{llllll}
\hline & $\mathrm{PM}_{2.5}$ & $\mathrm{NO}_{2}$ & $\mathrm{NH}_{3}$ & $\mathrm{SO}_{2}$ & $\mathrm{CO}$ \\
\hline Pre-lockdown & $188.77 \pm 82.17$ & $52.77 \pm 14.687$ & $6.667 \pm 2.179$ & $20.556 \pm 10.126$ & $36.889 \pm 12.150$ \\
Lockdown & $65.16 \pm 51.32$ & $33.66 \pm 12.56$ & $4.83 \pm 1.47$ & $10.500 \pm 4.929503$ & $35.500 \pm 23.96$ \\
Post-lockdown & $178.18 \pm 109.20$ & $66.78 \pm 37.76$ & $13.63 \pm 7.32$ & $13.87 \pm 7.82$ & $44.06 \pm 19.46$ \\
\% Inc. or dec & $65.48 \%$ & $36.21 \%$ & $27.55 \%$ & $48.92 \%$ & $3.76 \%$ \\
& Decrease & Decrease & Decrease & Decrease & Decrease \\
\hline
\end{tabular}

The Air Quality Index (AQI) became moderate during the lockdown period as compared to pre-lockdown and again worsened from October 2020 onwards (Fig. 1a). During the lockdown period i.e., from 1st April 2020 till 31st May
2020, the pollution parameters showed significant reduction to $\mathrm{PM}_{2.5} \quad\left(65.16 \pm 51.32 \mu \mathrm{g} / \mathrm{m}^{3}\right), \quad \mathrm{NO}_{2}$ $\left(33.66 \pm 12.56 \mu \mathrm{g} / \mathrm{m}^{3}\right), \quad \mathrm{NH}_{3}\left(4.83 \pm 1.47 \mu \mathrm{g} / \mathrm{m}^{3}\right), \mathrm{SO}_{2}$ $\left(10.50 \pm 4.92 \mu \mathrm{g} / \mathrm{m}^{3}\right)$ and $\mathrm{CO}\left(35.50 \pm 23.96 \mathrm{mg} / \mathrm{m}^{3}\right)$ as

a

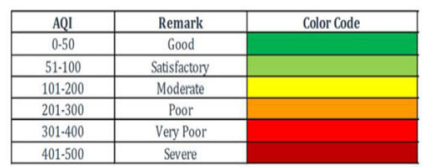

b

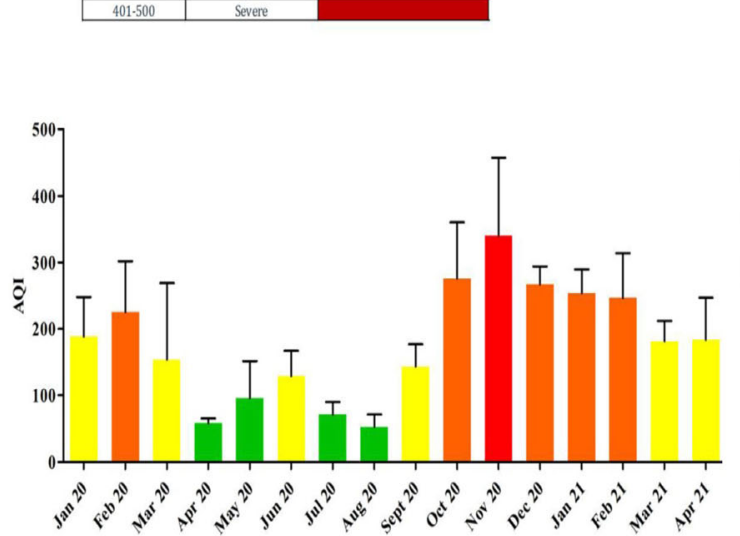

c

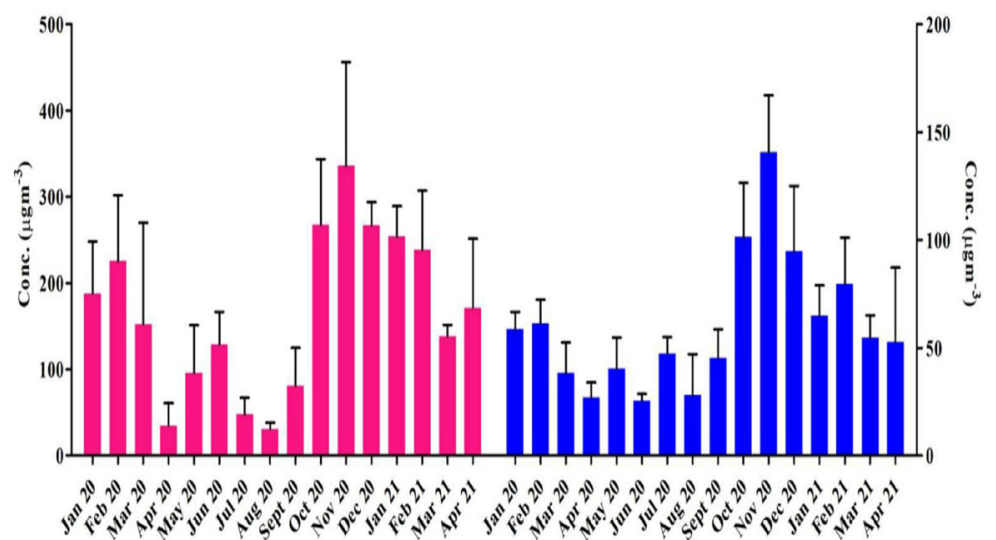

PM2.5 $\mathrm{N} 02$

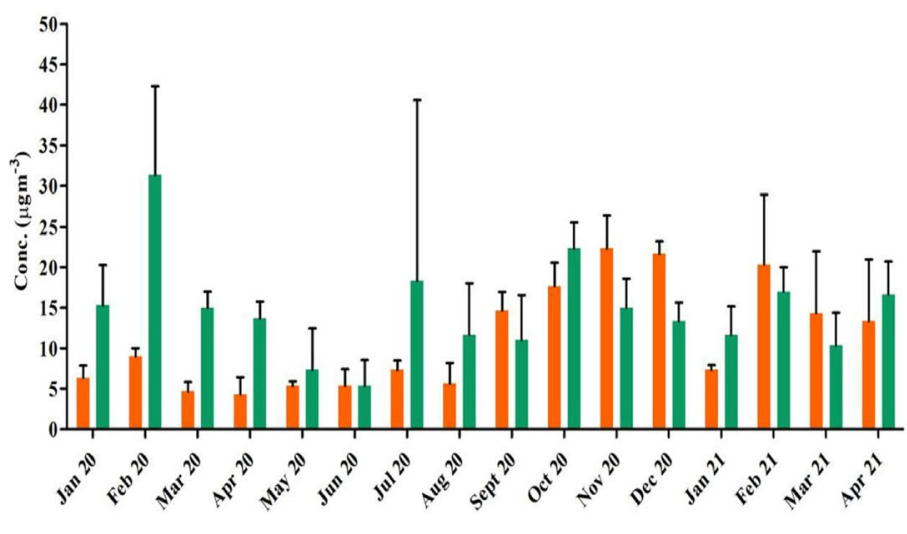

d index (AQI), b. $\mathrm{NH}_{3}$ and $\mathrm{SO}_{2}$, c. $\mathrm{PM}_{2.5}$ and $\mathrm{NO}_{2}$, d. Carbon monoxide 
shown in Table 1 (Fig. 1b, c, d). The pollutant level again showed a significant rise as soon as the lockdown period was over as denoted by the different pollutants. The pollutant level $\mathrm{PM}_{2.5}$ reached $178.18 \pm 109.20 \mu \mathrm{g} / \mathrm{m}^{3}, \mathrm{NO}_{2}$ $66.78 \pm 37.76 \mu \mathrm{g} / \mathrm{m}^{3}, \quad \mathrm{NH}_{3} \quad 13.63 \pm 7.32 \mu \mathrm{g} / \mathrm{m}^{3}, \quad \mathrm{SO}_{2}$ $13.87 \pm 7.82 \mu \mathrm{g} / \mathrm{m}^{3}$ and $\mathrm{CO} 44.06 \pm 19.46 \mathrm{mg} / \mathrm{m}^{3}$, during the post lockdown period as shown in Table 1. The AQI scale used by CPCB to monitor the pollutant level is shown in Table 2 (Fig. 1). NAQI provides a numerical value as well as color codes in which the values between 0 and 50 denote the air quality as good and hence will have minimal impact on health (shown by green color). Similarly, the values in the range 51-100 are considered as satisfactory shown by light green color, whereas the value in the range 101-200 is termed as moderately polluted (shown by yellow color), the situation where breathing discomforts start in sensitive people. The range $201-300$ is termed as poor quality air (orange color), followed by 301-400 (light red) which is very poor and 401-500 (dark red) as the most severe ones. As per the NAQI standards, the level of pollutant $\mathrm{PM}_{2.5}$ reached moderate from very poor due to the lockdown imposed due to COVID-19, whereas the pollutant $\mathrm{NO}_{2}$ reached the status good from satisfactory. The effect of lockdown on $\mathrm{SO}_{2}$ pollutant resulted in nearly half the emission whereas the pollutant $\mathrm{NH}_{3}$ and $\mathrm{CO}$ did not show much decline due to lockdown as the carbon monoxide emission was still severe. The level of these pollutants again becomes moderate for $\mathrm{PM}_{2.5}$ and $\mathrm{NO}_{2}$, satisfactory for $\mathrm{SO}_{2}$, whereas remained good for $\mathrm{NH}_{3}$ and severe for $\mathrm{CO}$.

\subsection{Statistical analysis of air quality parameters}

A one-way ANOVA test was used to examine the data in order to get a compelling conclusion on the "impact of lockdown on pollutant concentration," with the premise that mean pollutant concentration had no influence on lockdown. Table 3 describe the ANOVA findings for several parameters such as $\mathrm{PM}_{2.5}, \mathrm{NO}_{2}, \mathrm{NH}_{3}, \mathrm{CO}$, and $\mathrm{SO}_{2}$. The $\mathrm{p}$ value for all other parameters was less than 0.05 , indicating that lockdown had a substantial influence on the concentrations of most of the metrics, including $\mathrm{PM}_{2.5}$, $\mathrm{NO}_{2}, \mathrm{NH}_{3}, \mathrm{CO}$, and $\mathrm{SO}_{2}$. The ANOVA results of Air Quality parameters are shown in Table 3 which indicates that the parameters $\mathrm{PM}_{2.5}, \mathrm{NO}_{2}, \mathrm{NH}_{3}, \mathrm{CO}$, and $\mathrm{SO}_{2}$ were affected by the COVID-19 induced lockdown.

\subsection{Effect of lockdown on water quality index}

The impact of lockdown on the level of water pollution of Yamuna River was studied (map shown in Fig. 2), as the major sources of water pollution like industries, transportation, different power plants and other construction activities were stopped. This resulted in improvement of all river bodies in the country including the Yamuna River in Delhi. So, in this study we have analyzed the water quality in the form of $\mathrm{pH}$, DO (Dissolved Oxygen), COD (Chemical Oxygen Demand) and BOD (Biological Oxygen Demand) before, during and after the lockdown period (Table 4).

\subsection{Impact of lockdown on the pH of Yamuna river}

The impact of lockdown in this study was analysed during the pre, during and post-lockdown period. The average $\mathrm{pH}$ of Yamuna River was found to be alkaline with a $\mathrm{pH}$ of 7.3. During the pre-lockdown period the $\mathrm{pH}$ at village Palla and Nizamuddin Bridge was nearly 7.6 whereas that of Agra canal was 7.63 with a mean value of 7.57 (Fig. 3a). When the lockdown was imposed there was a slight increase in alkalinity of Yamuna River at village Palla with a $\mathrm{pH}$ of 8.0, whereas that of Nizamuddin Bridge and Agra canal was 7.64 and 7.45 respectively with a mean value of 7.69. After the lockdown, the $\mathrm{pH}$ at all these places decreased again and found similar to the pre-lockdown phase with a mean value of 7.36. The $\mathrm{pH}$ level was nearly in the threshold limit of 6.6-8.5, which is optimum for aquatic life and village Palla which is the entry point of Yamuna River recorded the highest $\mathrm{pH}$ of 8.0 during the lockdown period. The rise in the level of $\mathrm{pH}$ during the lockdown periods is probably due to the entry of organic waste products from anthropogenic sources into the water of river Yamuna in the urban areas. Therefore an alkaline $\mathrm{pH}$ was observed during the lockdown period. It is presumed that the industrial wastes composed of various ingredients which promote acidity.

\subsection{Chemical oxygen demand (COD) level in Yamuna river}

Chemical Oxygen Demand (COD) indicates the amount of dissolved susceptible matter and is an indicator of water pollution. The major sources which contribute to rise in COD values include effluents from industries and wastewater treatment plants which were on halt during the lockdown period. An increase in COD not only indicates pollution, but also severely affects the dissolved oxygen, ultimately affecting the aquatic life. During the pre-lockdown phase, the COD value ranged from 9 to $102.66 \mathrm{mg} / \mathrm{l}$ with a mean value of $62 \mathrm{mg} / \mathrm{l}$. The highest COD of $102.66 \mathrm{mg} / \mathrm{l}$ was recorded at Agra Canal and lowest at village Palla $(9 \mathrm{mg} / \mathrm{l})$ during the pre-lockdown phase as shown in Table 4 (Fig. 3b). However, there was significant reduction in the COD values during the lockdown period at all locations as it was observed between 12 to $48 \mathrm{mg} / \mathrm{l}$ with a mean value of $34 \mathrm{mg} / \mathrm{l}$. The maximum reduction in COD 
Table 2 National AQI and concentration ranges of the pollutants

\begin{tabular}{|c|c|c|c|c|c|c|}
\hline $\begin{array}{c}\text { AQI } \\
\text { Category }\end{array}$ & & \multicolumn{5}{|c|}{ Concentration range* } \\
\hline & AQI & $\mathbf{P M}_{\mathbf{2 . 5}}$ & $\mathbf{N O}_{\mathbf{2}}$ & $\mathbf{N H}_{\mathbf{3}}$ & $\mathbf{S O}_{\mathbf{2}}$ & $\mathbf{C O}$ \\
\hline Good & $0-50$ & $0-30$ & $0-40$ & $0-200$ & $0-40$ & $0-1.0$ \\
\hline Satisfactory & $51-100$ & $31-60$ & $41-80$ & $201-400$ & $41-80$ & $1.1-2.0$ \\
\hline Moderate & $101-200$ & $61-90$ & $81-180$ & $401-800$ & $81-380$ & $2.1-10$ \\
\hline Poor & $201-300$ & $91-120$ & $181-280$ & $801-1200$ & $381-800$ & $10-17$ \\
\hline Very Poor & $301-400$ & $121-250$ & $281-400$ & $1200-1800$ & $801-1600$ & $17-34$ \\
\hline Severe & $401-500$ & $250+$ & $400+$ & $1800+$ & $1600+$ & $34+$ \\
\hline
\end{tabular}

*CO in $\mathrm{mg} / \mathrm{m}^{3}$ and other pollutant in $\mu \mathrm{g} / \mathrm{m} 3 ;$ 24-hourly average values for $\mathrm{PM}_{2.5}, \mathrm{NO}_{2}, \mathrm{NH}_{3}$, and $\mathrm{SO}_{2}$, and 8 hourly values for $\mathrm{CO}$

was found at Agra canal during the lockdown phase followed by Nizamuddin Bridge. During the post-lockdown phase, there was slight increase in COD values of village Palla (12.4 mg/l), whereas the COD values at Nizamuddin Bridge and Agra Canal nearly doubled with respect to the lockdown period. During the post-lockdown phase, the COD value ranges from 12.4 to $92.4 \mathrm{mg} / \mathrm{l}$ with a mean value of $62 \mathrm{mg} / \mathrm{l}$.

\subsection{Dissolved oxygen level in Yamuna river}

Dissolved Oxygen (DO), an important indicator of water pollution is an important parameter as it severely affects aquatic life. The highest DO $(8.1 \mathrm{mg} / \mathrm{l})$ was recorded at Palla and lowest $(0 \mathrm{mg} / \mathrm{l})$ at Agra Canal (Jaitpur) during the pre-lockdown phase (Fig. 3c). During the pre-lockdown phase, the DO value ranges from 0 to $8.1 \mathrm{mg} / \mathrm{l}$ with a mean value of $3.2 \mathrm{mg} / \mathrm{l}$. Overall, the DO value ranges from 2.3 to $6.9 \mathrm{mg} / \mathrm{l}$ with a mean value of $4.46 \mathrm{mg} / \mathrm{l}$ during the lockdown period. During the lockdown period, there was an improvement in the DO levels of all the regions due to the halt in industrial and other pollution activities. As the lockdown period was over, the DO levels again declined except for village Palla which showed DO level of $7.0 \mathrm{mg} /$ 1. So, overall lockdown helped the aquatic life as the DO values showed a significant rise in level (except for Palla region). During the post-lockdown phase, the DO value ranges from 0.3 to $7.0 \mathrm{mg} / \mathrm{l}$ with a mean value of $2.89 \mathrm{mg} /$ 1.

\subsection{Biological oxygen demand (BOD) of Yamuna river}

Biological Oxygen Demand (BOD) is an important indicator of water pollution as more the BOD value, high is level of water pollution, as more oxygen is required to oxidize the organic wastes in water. The major contributors of BOD in Yamuna River include dead plant and animals as well as effluents from industries and power plants. BOD value varied from 2.7 to $34.66 \mathrm{mg} / \mathrm{l}$ with a mean value of $21.78 \mathrm{mg} / \mathrm{l}$ during the pre-lockdown phase while it observed between 2.8 and $17 \mathrm{mg} / \mathrm{l}$ with a mean value of $11.93 \mathrm{mg} / \mathrm{l}$ during the lockdown phase as shown in Fig. 3d. The highest BOD (34.66 mg/l) was recorded at Agra Canal (Jaitpur) and lowest $(2.7 \mathrm{mg} / \mathrm{l})$ at village Palla during the pre-lockdown phase which showed significant decline during the lockdown phase due to the decrease in industrial activities as well as the prevailing weather conditions (Table 3). The BOD value again showed an increment during the post-lockdown phase where the BOD varied from 2.07 to $29.8 \mathrm{mg} / \mathrm{l}$ with a mean value of $18.19 \mathrm{mg} / \mathrm{l}$. Overall, the BOD ranges were quite higher than the threshold limit $(3 \mathrm{mg} / \mathrm{l})$ during the pre-lockdown phase, which has hazardous impact on all biological processes in water and ultimately affects aquatic life.

\subsection{Statistical analysis of water quality parameters}

A one-way ANOVA test was used to examine the data in order to get a compelling conclusion on the "impact of lockdown on pollutant concentration," with the premise that mean pollutant concentration had no influence on lockdown. Table 5 describes the ANOVA findings for several parameters such as $\mathrm{pH}, \mathrm{BOD}, \mathrm{COD}$ and DO. The $\mathrm{p}$ value for all other parameters was less than 0.05 , indicating that lockdown had a substantial influence on the concentrations of most of the metrics, including $\mathrm{pH}$, BOD, COD and DO. The ANOVA results of Water Quality parameters are shown in Table 5 which indicates that the parameters $\mathrm{pH}, \mathrm{BOD}, \mathrm{COD}$ and DO were affected by the COVID-19 induced lockdown. 
Table 3 Analysis of variance for $\mathrm{AQI}, \mathrm{PM}_{2.5}, \mathrm{SO}_{2}, \mathrm{NO}_{2}, \mathrm{NH}_{3}$ and $\mathrm{CO}$

\begin{tabular}{|c|c|c|c|c|c|c|}
\hline & & Sum of squares & $\mathrm{df}$ & Mean square & $F$ & Sig \\
\hline \multirow[t]{3}{*}{ AQI } & Between groups & 3827 & 2 & 1913 & 0.1928 & 0.000 \\
\hline & Within groups & 446,548 & 45 & 9923 & & \\
\hline & Total & 450,375 & 47 & & & \\
\hline \multirow[t]{3}{*}{$\mathrm{PM}_{2.5}$} & Between groups & 4285 & 2 & 2143 & 0.1872 & 0.000 \\
\hline & Within groups & 515,131 & 45 & 11,447 & & \\
\hline & Total & 519,416 & 47 & & & \\
\hline \multirow[t]{3}{*}{$\mathrm{SO}_{2}$} & Between groups & 73.17 & 2 & 36.58 & 0.5042 & 0.000 \\
\hline & Within groups & 3265 & 45 & 72.55 & & \\
\hline & Total & 3338 & 47 & & & \\
\hline \multirow[t]{3}{*}{$\mathrm{NO}_{2}$} & Between groups & 1037 & 2 & 518.6 & 0.4381 & 0.000 \\
\hline & Within groups & 53,272 & 45 & 1184 & & \\
\hline & Total & 54,309 & 47 & & & \\
\hline \multirow[t]{3}{*}{$\mathrm{NH}_{3}$} & Between groups & 37.04 & 2 & 18.52 & 0.3544 & 0.000 \\
\hline & Within groups & 2351 & 45 & 52.25 & & \\
\hline & Total & 2388 & 47 & & & \\
\hline \multirow[t]{3}{*}{$\mathrm{CO}$} & Between groups & 10.04 & 2 & 5.021 & 0.01346 & 0.000 \\
\hline & Within groups & 16,785 & 45 & 373.0 & & \\
\hline & Total & 16,795 & 47 & & & \\
\hline
\end{tabular}

Fig. 2 Showing different pollution sources of Yamuna River, and their locations ( Source: CPCB, 2020)

\subsection{Impact of lockdown on COVID-19 cases as well as deaths}

To study the affect of pandemic induced lockdown on the confirmed and cured cases of COVID-19 disease in Delhi, the data for total number of confirmed cases, number of deaths as well as cured cases before, during and postlockdown was gathered from website (https://www.kaggle. com). During the pre-lockdown phase the cases as well as deaths were low as the disease has just arrived India, but 
Table 4 Comparative analysis of various water quality index parameters during pre-

lockdown, lockdown and Post lockdown phases and their change at different hotspot locations of Yamuna River in Delhi

\begin{tabular}{llllll}
\hline Location & Phase & $\begin{array}{l}\mathrm{pH} \\
(\text { Mean }+\mathrm{SD})\end{array}$ & $\begin{array}{l}\text { COD } \\
(\text { Mean }+\mathrm{SD})\end{array}$ & $\begin{array}{l}\text { BOD } \\
(\text { Mean }+\mathrm{SD})\end{array}$ & $\begin{array}{l}\text { DO } \\
(\text { Mean }+ \text { SD) }\end{array}$ \\
\hline Palla & Pre-lockdown & $7.60 \pm 0.20$ & $9.00 \pm 1.00$ & $2.70 \pm 0.26$ & $8.13 \pm 0.73$ \\
& Lockdown & $8.00 \pm 0.20$ & $12.00 \pm 1.50$ & $2.80 \pm 0.15$ & $6.90 \pm 0.23$ \\
& Post-lockdown & $7.62 \pm 0.41$ & $12.40 \pm 6.31$ & $2.07 \pm 0.98$ & $7.00 \pm 1.74$ \\
& \% Inc. or dec & $5.26 \%$ & $33.33 \%$ & $3.70 \%$ & $15.12 \%$ \\
& & Increase & Increase & Increase & Decrease \\
Nizamudin bridge & Pre-lockdown & $7.63 \pm 0.11$ & $77.33 \pm 2.30$ & $28.00 \pm 4.00$ & $1.53 \pm 0.63$ \\
& Lockdown & $7.64 \pm 0.35$ & $42.00 \pm 0.80$ & $16.00 \pm 0.30$ & $2.30 \pm 0.38$ \\
& Post-lockdown & $7.20 \pm 0.32$ & $81.40 \pm 32.51$ & $22.70 \pm 8.60$ & $1.39 \pm 1.60$ \\
& \% Inc. or dec & $0.13 \%$ & $45.68 \%$ & $42.85 \%$ & $50.32 \%$ \\
& & Increase & Decrease & Decrease & Increase \\
Agra canal (Jaitpur) & Pre-lockdown & $7.50 \pm 0.45$ & $102.66 \pm 37.16$ & $34.66 \pm 13.20$ & $0.00 \pm 0.00$ \\
& Lockdown & $7.45 \pm 0.60$ & $48.00 \pm 0.75$ & $17.00 \pm 0.60$ & $4.20 \pm 0.59$ \\
& Post-lockdown & $7.32 \pm 0.36$ & $92.40 \pm 34.40$ & $29.80 \pm 14.25$ & $0.30 \pm 0.63$ \\
& \% Inc. or dec & $0.66 \%$ & $53.24 \%$ & $50.95 \%$ & \\
\hline
\end{tabular}

b
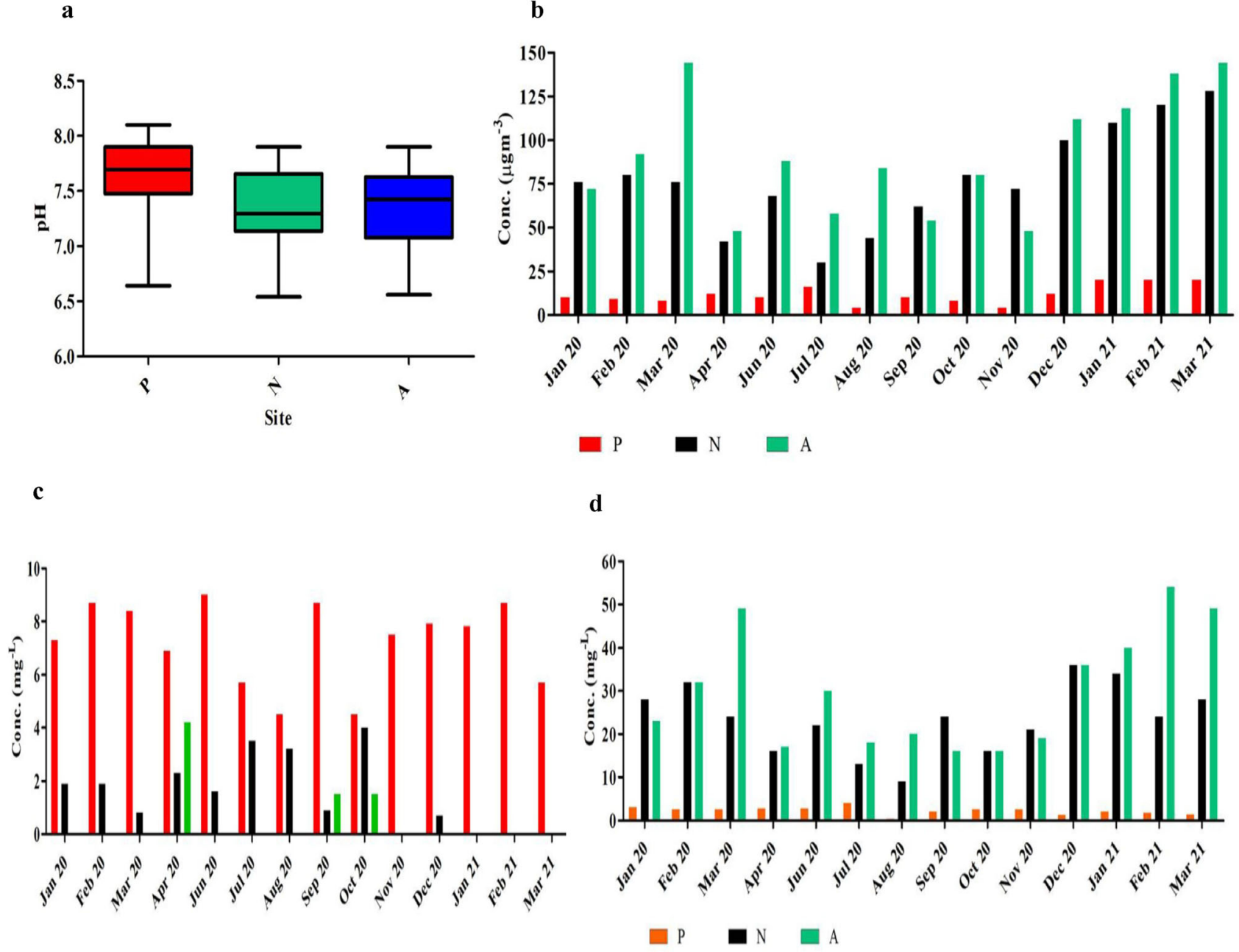

Fig. 3 Monthly variation of water pollutants in Yamuna River, Delhi, India during the period of pre-lockdown, during lockdown and postlockdown. a. $\mathrm{pH}, \mathbf{b}$. COD, c. DO, d. BOD where, $\mathrm{P}$ stands for village Palla, $\mathrm{N}$ for Nizamuddin bridge and A for Agra canal 
post-lockdown the cases increased at much higher rates with increased fatality. The lockdown had positive impact as the number of cases as well as death rate was quite low as compared to post-lockdown period as shown in Fig. 4 . After the post-lockdown period the country witnessed a second wave of COVID-19 pandemic where the cases and deaths reached an uncontrolled limit.

\section{Discussion}

Due to rapid urbanization, industrialization and reckless use of natural resources by anthropogenic activities, environmental pollution have become major challenges all over the world. Degradation of air and water quality, especially in urban areas is the result of improper or haphazard developments. Continuous decline in the quality of air especially in the megacities across the nation has led to the eruption of several severe respiratory disorders. The main reason behind the abrupt rise in the air pollution is the incomplete or partial combustion of fossil fuels by vehicular transportation, industrial operations as well as generation of huge amount of domestic or anthropogenic waste products [19]. In the Mid-March of 2020, Indian Government has imposed nationwide lockdown to curb the rapid spread of COVID-19 pandemic. Although, it seems that COVID-19 induced lockdown has shown its devastating effects on global economy, however, environments rejuvenate itself in this short span of time temporarily from the excessive exploitation by humans [20].

Recent studies have shown that significant reduction in many pollutants has been recorded almost every regions of India during the period of lockdown. Das et al. (2020) [21] have reported that significant decline (35\%) in the concentration of $\mathrm{PM}_{2.5}$ was observed in the cities located in the Indo-Gangetic Plain after declaration of lockdown. Levels of pollutants in Delhi during the lockdown periods were recorded minimum of last 5 years level [22]. The data of our study showed similar results where we observed the concentration (average) of different pollutants before the lockdown (From January to March 2020) was $\mathrm{PM}_{2.5}$ $\left(188.77 \pm 82.17 \mu \mathrm{g} / \mathrm{m}^{3}\right), \quad \mathrm{NO}_{2} \quad\left(52.77 \pm 14.68 \mu \mathrm{g} / \mathrm{m}^{3}\right)$, $\mathrm{NH}_{3}\left(6.66 \pm 2.17 \mu \mathrm{g} / \mathrm{m}^{3}\right) \mathrm{SO}_{2}\left(20.55 \pm 10.12 \mu \mathrm{g} / \mathrm{m}^{3}\right)$ and $\mathrm{CO}\left(36.88 \pm 10.12 \mathrm{mg} / \mathrm{m}^{3}\right)$ as shown in (Table 1). During the lockdown period (from 1st April 2020 till 31st May 2020), the concentration of different air quality pollutant parameters showed significant reduction in $\mathrm{PM}_{2.5}$ $\left(65.16 \pm 51.32 \mu \mathrm{g} / \mathrm{m}^{3}\right), \mathrm{NO}_{2}\left(33.66 \pm 12.56 \mu \mathrm{g} / \mathrm{m}^{3}\right), \mathrm{NH}_{3}$ $\left(4.83 \pm 1.47 \mu \mathrm{g} / \mathrm{m}^{3}\right), \mathrm{SO}_{2}\left(10.50 \pm 4.92 \mu \mathrm{g} / \mathrm{m}^{3}\right)$ and $\mathrm{CO}$ $\left(35.50 \pm 23.96 \mathrm{mg} / \mathrm{m}^{3}\right)$ as shown in Table 1 (Fig. 2b-d). The Air Quality parameters improves during the lockdown period and hence became moderate as compared to pre- lockdown and again worsened from October 2020 onwards (Fig. 2a).

The $\mathrm{pH}$ of water is an important indicator of water quality. It represents concentration of hydrogen ion in the water. The BIS (Bureau of Indian Standard) standard limit of $\mathrm{pH}$ for drinking water as well as for aquatic life is 6.5. Before lockdown, ranges of $\mathrm{pH}$ were recorded from 7.5 to 7.63 with mean value of 7.57 . Whereas during the lockdown period, the $\mathrm{pH}$ level ranges from 7.45 to 8 with an average of 7.69. After completion of lockdown the $\mathrm{pH}$ was recorded 7.3-7.6 with mean value of 7.36. Due to less mixing of industrial effluents, $\mathrm{pH}$ in the unlock period was recorded alkaline. Similar results have also been documented previously by Peter (2009) [23] and Mocellin and Magro (2011) [24].

Chemical oxygen demand (COD) is the estimate of $\mathrm{O}_{2}$ needed for the part of organic matter in polluted water which is subjected to oxidation. COD indicates water quality, used to determine the actual amount of biologically active matters in water. High COD concentration is responsible for fast degradation of $\mathrm{O}_{2}$ in water bodies and decreases oxygen availability for aquatic life forms. BIS desirable limit of COD for aquatic life as well as drinking water is $120 \mathrm{mg} / \mathrm{l}$. In the pre-lockdown COD ranged from 9 to $102 \mathrm{mg} / \mathrm{l}$ with a mean value of $62 \mathrm{mg} / \mathrm{l}$. During the lockdown period, less mixing of organic chemicals helped in decreasing BOD level in Yamuna river water and recorded as $12-48 \mathrm{mg} / \mathrm{l}$ with an average value of 34 . While post lockdown period recorded 12.4-92.4 mg/l of BOD with average of 62 in river water.

Dissolve oxygen indicates oxygen availability in water. Good quality of water contains higher rate of DO. BIS permissible limit of DO for aquatic life as well as drinking water is above $6 \mathrm{mg} / \mathrm{l}$. In the pre-lockdown DO ranged from 0 to $8.1 \mathrm{mg} / \mathrm{l}$ with a mean value of $3.2 \mathrm{mg} / \mathrm{l}$. During the lockdown period, as a consequence of less amount of mixing of organic chemicals, decreasing DO level in Yamuna river water and recorded as $2.3-6.9 \mathrm{mg} / \mathrm{l}$ with an average value of 4.46. In contrast, during the post lockdown period the concentration of DO was recorded $0.34-7 \mathrm{mg} / \mathrm{l}$ with average of 2.89 in river water.

Biological oxygen demand (BOD) is considered as a crucial water quality parameter. Greater level of BOD indicates very poor water quality. BIS recommended value of BOD for aquatic life as well as drinking water is $5 \mathrm{mg} / \mathrm{l}$. Increased level of BOD indicates the river water is highly polluted. In the pre-lockdown BOD ranged from 2.7 to $34.66 \mathrm{mg} / \mathrm{l}$ with a mean value of $21.78 \mathrm{mg} / \mathrm{l}$. During the lockdown period, less mixing of organic chemicals helped in decreasing BOD level in Yamuna river water and recorded as $2.8-17 \mathrm{mg} / \mathrm{l}$ with an average value of 11.93 . While post lockdown period recorded $2.07-29.8 \mathrm{mg} / \mathrm{l}$ of BOD with average of 18.19 in river water. 
Table 5 Analysis of variance for BOD, COD, DO and $\mathrm{pH}$

\begin{tabular}{|c|c|c|c|c|c|c|}
\hline & & Sum of squares & $\mathrm{df}$ & Mean square & $F$ & Sig \\
\hline \multirow[t]{3}{*}{ BOD } & Between groups & 5852 & 2 & 2926 & 35.18 & $<0.0001$ \\
\hline & Within groups & 3244 & 39 & 83.19 & & \\
\hline & Total & 9097 & 41 & & & \\
\hline \multirow[t]{3}{*}{ COD } & Between groups & 50,957 & 2 & 25,478 & 36.78 & $<0.0001$ \\
\hline & Within groups & 27,013 & 39 & 692.7 & & \\
\hline & Total & 77,970 & 41 & & & \\
\hline \multirow[t]{3}{*}{ DO } & Between groups & 369.5 & 2 & 184.8 & 96.63 & $<0.0001$ \\
\hline & Within groups & 74.57 & 39 & 1.912 & & \\
\hline & Total & 444.1 & 41 & & & \\
\hline \multirow[t]{3}{*}{$\mathrm{pH}$} & Between groups & 0.8188 & 2 & 0.4094 & 3.212 & 0.000 \\
\hline & Within groups & 4.971 & 39 & 0.1275 & & \\
\hline & Total & 5.790 & 41 & & & \\
\hline
\end{tabular}

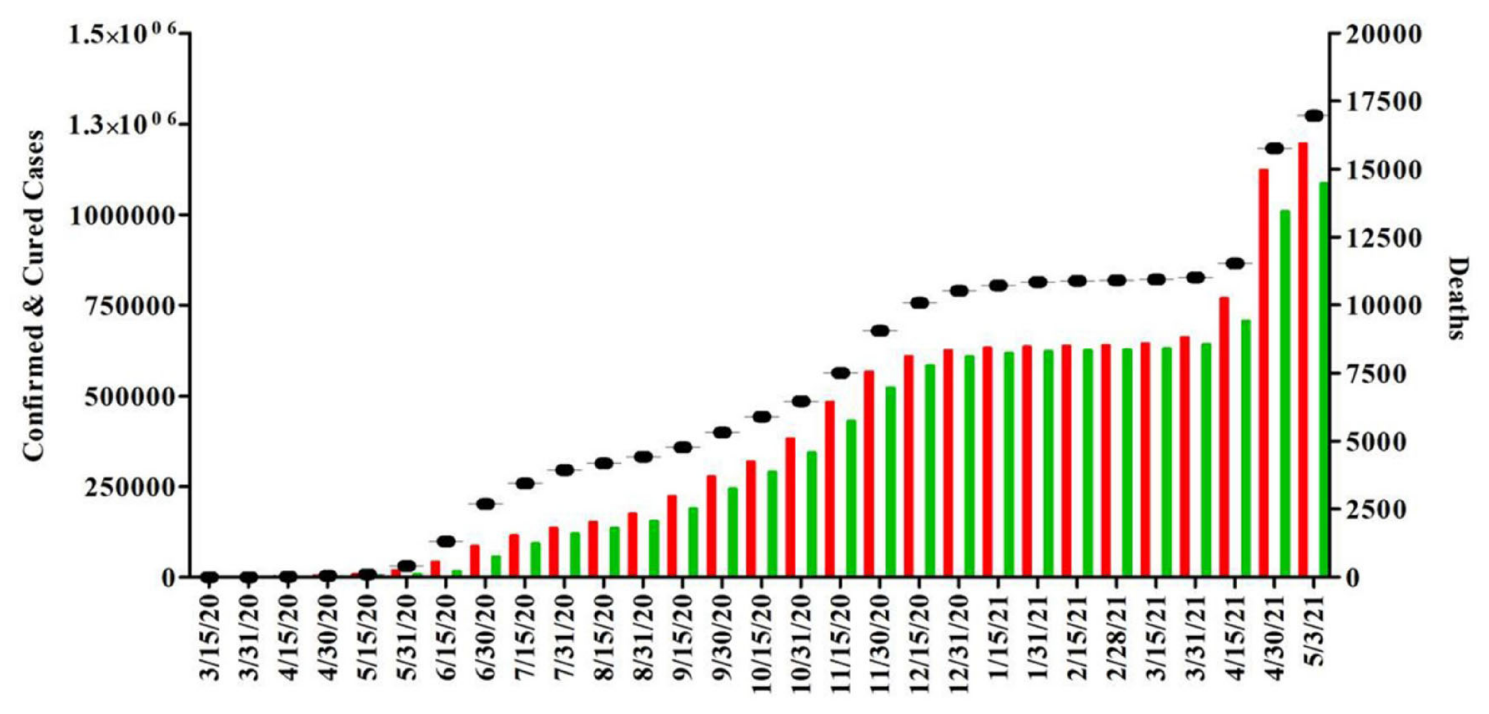

Cured

$$
\text { Confirmed - Deaths }
$$

Fig. 4 Monthly variation in the number of confirmed COVID-19 cases, cured cases as well as deaths in Delhi, India during the period of prelockdown, during lockdown and post-lockdown. A dark line indicates the pre and post lockdown phase of COVID-19 pandemic

The findings of present work showing the impact of lockdown on the water quality parameters of river Yamuna in Delhi national capital territory. Zargar (2019) [25] has reported that the conditions of Yamuna's water quality amid lockdown was appeared much better than its earlier toxic status where the foam was found all around the channel. It was quite evident from the results of our study that there is a significant improvement in the Yamuna WQI, like pH, DO, BOD, COD, when compared with the pre-lockdown conditions and found consistent with the reports of Jha D. (2020a) [26]. Yamuna river is known to be the highly polluted rivers in India, mainly in Delhi region [13]. The recent analysis reflected that the considerable decline in the water pollution of Yamuna River has been observed during the lockdown phase.

COVID-19 brought a lot of negative impacts on millions of lives, however, it has a significant positive effect on nature and the environment [27]. The declaration of SARSCoV-2 induced lockdown improves the quality of air and water in a short time interval because of temporary suspension of industries, factories, transportation and human activities which are the major cause of pollution [28, 29]. Enforcement of lockdown in countries like France, Germany, Spain, Italy, China, India led to temporary closure of industries and transportation as a result of which concentration of green house gases, nitrogen dioxide, $\mathrm{PM}_{2.5}, \mathrm{PM}_{10}$ and $\mathrm{CO}$ decreased drastically [30]. The lockdown brought 
good signs for the deadly global environment and the absence of human imparted positive effects [31]. Back before COVID-19, the biggest concern was pollution and various agencies worked all over the world to reduce pollution levels especially urban pollution in the form of carbon dioxide, nitrogen dioxide, sulphur dioxide and particulate matter [32]. According to the report of WHO, 2016 almost $8 \%$ of total deaths in the world occurred due to air pollution. Zambrano-Monserrateet et al. (2020) [33] have reported that AQI (Air Quality Index) in North, South, East, Central and Western part of India dipped by $44 \%, 33 \%, 29 \%, 15 \%$ and $32 \%$ respectively. The capital of India, Delhi recorded the reduction of almost $70 \%$ in the levels of nitrogen dioxide and $\mathrm{PM}_{2.5}$ [34]. Rivers mainly Ganga and Yamuna in India were seen clearer and significant reduction in water pollution [35] was observed.

Similarly, during the pre-lockdown phase the COVID19 positive cases and causalities were recorded low because the disease has just came India, while during the post-lockdown period the cases increased at much higher rates with increased mortality. It is clearly evident from the data of our study that lockdown had positive impact, as the number of cases as well as death rate was recorded low after implementation of lockdown as compared to postlockdown period. After the post-lockdown period the country witnessed the emergence of second wave of COVID-19 pandemic where the cases and deaths reached an uncontrolled limit.

In summary, the marked improvements in the water and air quality indices are the positive outcomes of the COVID19 induced lockdown. This lockdown exhibited the solutions for the natures' rejuvenation by means of natural resource preservation as well as sustainable development. Thus, present investigation will draw the attention of the policymakers to introduce strict integrative plans to minimize the water as well as air pollution together using better regulatory and robust technological interventions.

\section{Conclusion}

Overall, the present study revealed that the implementation of lockdown appears to show pronounced improvement in the air quality indices in the densely populated metropolitan city such as New Delhi (India). Our study also highlighted the water quality parameters which were found beyond the permissible range during the pre and post lockdown periods that were significantly improved during the lockdown period. Therefore, it may be concluded that lockdown imposed due to COVID-19 has brought noticeable transformation for Yamuna River, and it has appeared to be a positive sign for nature's rejuvenation. Similarly, lockdown has also improved the recovery rate of patients and, therefore, helped in breaking the chain of COVID-19. The findings of this study will assist the regulatory bodies to devise a pathway on how to strictly minimize vehicular and industrial pollution adequately in several big cities to improve air and water quality that in turn help to sustain better public health around the world.

Acknowledgements The authors are grateful to Central Pollution Control Board (CPCB) for making available the data at the various locations of Delhi National Capital Region, related to air quality as well as water quality parameters.

Funding No funding received for this work.

Data availability The data utilized in this study has been acquired from the freely available source.

\section{Declarations}

Conflict of interest All the authors declare they have no conflict of interest.

Ethical statement The study presented here does not involve any work on animals or human.

\section{References}

1. Huang, C., Wang, Y., Li, X., Ren, L., Zhao, J., Hu, Y., Zhang, L., Fan, G., Xu, J., Gu, X., Cheng, Z., Yu, T., Xia, J., Wei, Y., Wu, W., Xie, X., Yin, W., Li, H., Liu, M., ... Cao, B. (2020). Clinical features of patients infected with 2019 novel coronavirus in Wuhan, China. Lancet (London, England), 395(10223), 497-506. https://doi.org/10.1016/S0140-6736(20)30183-5

2. Lu, H., Stratton, C. W., \& Tang, Y. W. (2020). Outbreak of pneumonia of unknown etiology in Wuhan, China: The mystery and the miracle. Journal of Medical Virology, 92(4), 401-402. https://doi.org/10.1002/jmv.25678

3. Guan, W. J., Ni, Z. Y., Hu, Y., Liang, W. H., Ou, C. Q., He, J. X., Liu, L., Shan, H., Lei, C. L., Hui, D., Du, B., Li, L. J., Zeng, G., Yuen, K. Y., Chen, R. C., Tang, C. L., Wang, T., Chen, P. Y., Xiang, J., ... China Medical Treatment Expert Group for Covid19. (2020). Clinical characteristics of coronavirus disease 2019 in China. The New England Journal of Medicine, 382(18), 1708-1720. https://doi.org/10.1056/NEJMoa2002032

4. World Health Organization. (2020). Coronavirus disease 2019 situation report 51, WHO Bull

5. Hu, B., Guo, H., Zhou, P., et al. (2021). Characteristics of SARSCoV-2 and COVID-19. Nature Reviews Microbiology, 19, 141-154. https://doi.org/10.1038/s41579-020-00459-7

6. Chen, L. A., Chien, L. C., Li, Y., \& Lin, G. (2020). Nonuniform impacts of COVID-19 lockdown on air quality over the United States. The Science of the total environment, 745, 141105. https:// doi.org/10.1016/j.scitotenv.2020.141105

7. Berman, J. D., \& Ebisu, K. (2020). Changes in US air pollution during the COVID-19 pandemic. The Science of the Total Environment, 739, 139864. https://doi.org/10.1016/j.scitotenv.2020. 139864

8. Mahato, S., Pal, S., \& Ghosh, K. G. (2020). Effect of lockdown amid COVID-19 pandemic on air quality of the megacity Delhi, India. The Science of the Total Environment, 730, 139086. https:// doi.org/10.1016/j.scitotenv.2020.139086 
9. Sharma, S., Zhang, M., Anshika, Gao, J., Zhang, H., \& Kota, S. H. (2020). Effect of restricted emissions during COVID-19 on air quality in India. The Science of the Total Environment, 728, 138878. https://doi.org/10.1016/j.scitotenv.2020.138878

10. Mani, KAS. (2020). The lockdown cleaned the Ganga more than 'Namami Gange' ever did. 19th April. Science The Wire. https:// science.thewire.in/environment/ganga-riverlockdown-cleanernamami-gange-sewage-treatment-ecological-flow/

11. Shukla, N., \& Srivastava, S. (2020). Lockdown impact: Ganga water in Haridwar becomes 'fit to drink' after decades. 22nd April. India Today https://www.indiatoday.in/india/ story/lockdown-impact-ganga-water-in-haridwar-becomes-fit-to-drinkafter-decades-1669576-2020-04-22

12. Shukla, RR., \& Gupta, N. (2020). How river Yamuna cleaned itself in 60 days of coronavirus lockdown. 25th May. NDTV https://www.ndtv.com/india-news/coronavirus-lockdownyamuna-cleanest-in-30-years-as-industrial-dumping-halts2234790.

13. Upadhyay, R., Dasgupta, N., Hasan, A., \& Upadhyay, S. K. (2011). Managing water quality of River Yamuna in NCR Delhi. Physics and Chemistry of the Earth, 36, 372-378. https://doi.org/ 10.1016/j.pce.2010.03.018

14. Sudalai Raj, Kumar., \& KP, Deva, Kumar. (2020, March 16). Retrieved from https://www.kaggle.com/sudalairajkumar/ covid19-in-india?select=covid_19_india.csv.

15. Central Control Room for Air Quality Management (2020). All India continuous stations status, national air quality index. Central pollution control board, Ministry of environment, Forest and climate change, Government of India. Retrieved from https://app. cpcbccr.com/ ccr/\#/caaqm-dashboard-all/caaqm-landing

16. CPCB (2020). Report on impact of lockdown on River Yamuna water quality. Retrieved from https://cpcb.nic.in/index.php

17. CPCB (2020). Daily river water quality monitoring data. Central pollution control board, Ministry of environment, forest and climate change, Government of India

18. National Air Quality Index (2014). Report of the expert committee. Control of urban pollution series (CUPS/82 /2014-15)Central pollution control board, Ministry of environment, Forest and climate change, Government of India. Retrieved from https:// app.cpcbccr.com/ ccr_docs/FINAL-REPORT_AQI_pdf

19. Popescu, F., \& Lonel, I. (2010). Anthropogenic air pollution sources. Anthropogen. Air Pollut Sources Air Qual. Ashok Kumar IntechOpen. Doi: https://doi.org/10.5772/9751.

20. Ndegwa, S. (2020). An environmental silver lining amid COVID19 cloud. China global television network, opinion. Retrieved from https://news.cgtn.com/news/2020-06-06/An-environmentalsilver-lining-amid-COVID-19-cloud-R4TpEvr0ty/index.html.

21. Das, M., Das, A., \& Mandal, A. (2020). Examining the impact of lockdown (due to COVID-19) on domestic violence (DV): An evidences from India. Asian Journal of Psychiatry. https://doi. org/10.1016/j.ajp.2020.102335

22. Jacob, K. (2020). Coronavirus lockdown lifts Delhi's air quality to 5-year high. The Hindu, News, Cities, Delhi (April 3, 2020). https://www.thehindu.com/news/cities/Delhi/coronavirus- lockdown-lifs-delhis-march-air-quality-to-5-year-high/arti cle31252221.ece

23. Peters, N. E. (2009). Effects of urbanization on stream water quality in the city of Atlanta, Georgia, USA. Hydrology Processes, 23, 2860-2878. https://doi.org/10.1002/hyp.7373

24. Mocellin, D. J. C., \& Magro, J. D. (2011). Influence of urbanisation on water quality in the basin of the upper Uruguay River in western Santa Catarina, Brazil. Acta Limnologica Brasiliensia, 23(2), 189-199.

25. Zargar, A.R. (2019). Hindu festival in India marred by a river of toxic foam and a blanket of killer smog. CBS News, 5th November. Available at: https://www.cbsnews.com/ news/yamuna-rivers-toxic-foam-and-delhi-air-pollution-greet-indiahindu-devotees-for-chhath-puja-festival/

26. Jha, D. (2020a). Najafgarh drain's biochemical oxygen demand reduces 40 points during lockdown: GMDA affidavit. 16th April. Available at. Hindustan Timeshttps://www.hindustantimes.com/ gurugram/najafgarh-drain-s-biochemical-oxygen-demand-redu ces-40 points-during-lockdown-gmda-affidavit/story6GSyjhwvrDQTu3y0b7YTsN.html

27. Ghosh, S., \& Ghosh, S. (2020). Air quality during covid-19 lockdown: Blessing in disguise. Indian Journal of Biochemistry \& Biophysics, 57, 420-430.

28. Gautam, S. (2020). The influence of COVID-19 on air quality in India: A boon or inutile. Bulletin of Environmental Contamination and Toxicology, 104(6), 724-726.

29. Srivastava, S., Kumar, A., Bauddh, K., Gautam, A. S., \& Kumar, S. (2020). 21-day lockdown in India dramatically reduced air pollution indices in Lucknow and New Delhi, India. Bulletin of Environmental Contamination and Toxicology, 105(1), 9-17.

30. Nigam, R., Pandya, K., Luis, A. J., Sengupta, R., \& Kotha, M. (2021). Positive effects of COVID-19 lockdown on air quality of industrial cities (Ankleshwar and Vapi) of Western India. Scientific Reports, 11(1), 4285.

31. Khan, I., Shah, D., \& Shah, S. S. (2021). COVID-19 pandemic and its positive impacts on environment: An updated review. International Journal of Environmental Science and Technology, $18,521-530$.

32. Arora, S., Bhaukhandi, K. D., \& Mishra, P. K. (2020). Coronavirus lockdown helped the environment to bounce back. Science of The Total Environment, 42, 140573.

33. Zambrano-Monserrate, M. A., Ruanob, M. A., \& Sanchez-Alcalde, L. (2020). Indirect effects of COVID-19 on the environment. Science of the Total Environment, 728, 138813.

34. Thiessen, T. (2020). How clean air cities could outlast COVID-19 lockdowns. https://www.forbes.com/sites/tamarathiessen/2020/ 04/10/how-clean-air-cities-could-outlast-covid-19-lockdowns/ \#292a5e866bb5. Accessed 13th Apr 2020.

35. Das, S. S. (2021). Positive impact of Covid-19 lockdown on environment. Gorteria Journal, 34(2), 112-119.

Publisher's Note Springer Nature remains neutral with regard to jurisdictional claims in published maps and institutional affiliations. 